\title{
Zeal for dermatology leads the way
}

\section{Raising awareness and finding the cure for skin cancer}

By: Kristinah K Krishnasamy

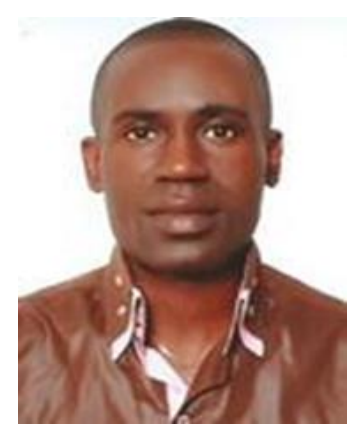

Dr. Kassi Komenan

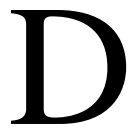

r. Kassi Komenan's journey in medical field started when he was offered to pursue his doctorate studies in general medicine at University of Abidjan, Ivory Coast. When asked what influenced him to choose this profession, he says in an exclusive interview with the JSD media team, "My passion to help those in need back in my hometown has guided me into choosing a career path in the field of dermatology."

After completing his foundation in general medicine, Dr. Komenan furthered his studies by specializing in dermatology-venerology and skin surgery under a national scholarship. "I was nationally selected for my internship in dermatology," he says. "Four years later, I was selected to be a lecturer at the University of Abidjan in 2006."

In 2009, Dr. Komenan was then offered a Hubert $\mathrm{H}$. Humphrey Fellowship, a prestigious American program offering valuable opportunities for leadership develop- ment and professional engagement. "My stay started in Tucson, Arizona, where I did my intensive English courses. After two months, I moved to Atlanta, Georgia, to start my program. During this program, I got the opportunity to meet the former president of USA Jimmy Carter and spent some moments with him," Dr. Komenan recalls.

He received his public health policy and prevention certificate, together with the knowledge that he obtained in skin cancers, cosmetic and dermatologic surgery at Emory University Hospital in Atlanta. At the same time, he expanded his knowledge by receiving training on wound care at Emory University's Wesley Wood Center as well as a training at the Center of Disease Control in Atlanta. Dr. Komenan also participated in several congresses, scientific meetings and courses when he was in US.

At the end of the Hubert H. Humphrey program, he received a congratulatory award signed by President Barack Obama and then-Secretary of State Hillary Clinton. The program ignited a fire in him to help the poor community in his hometown. "When I was back to my country, I created an NGO called VLIAC (Ivorian

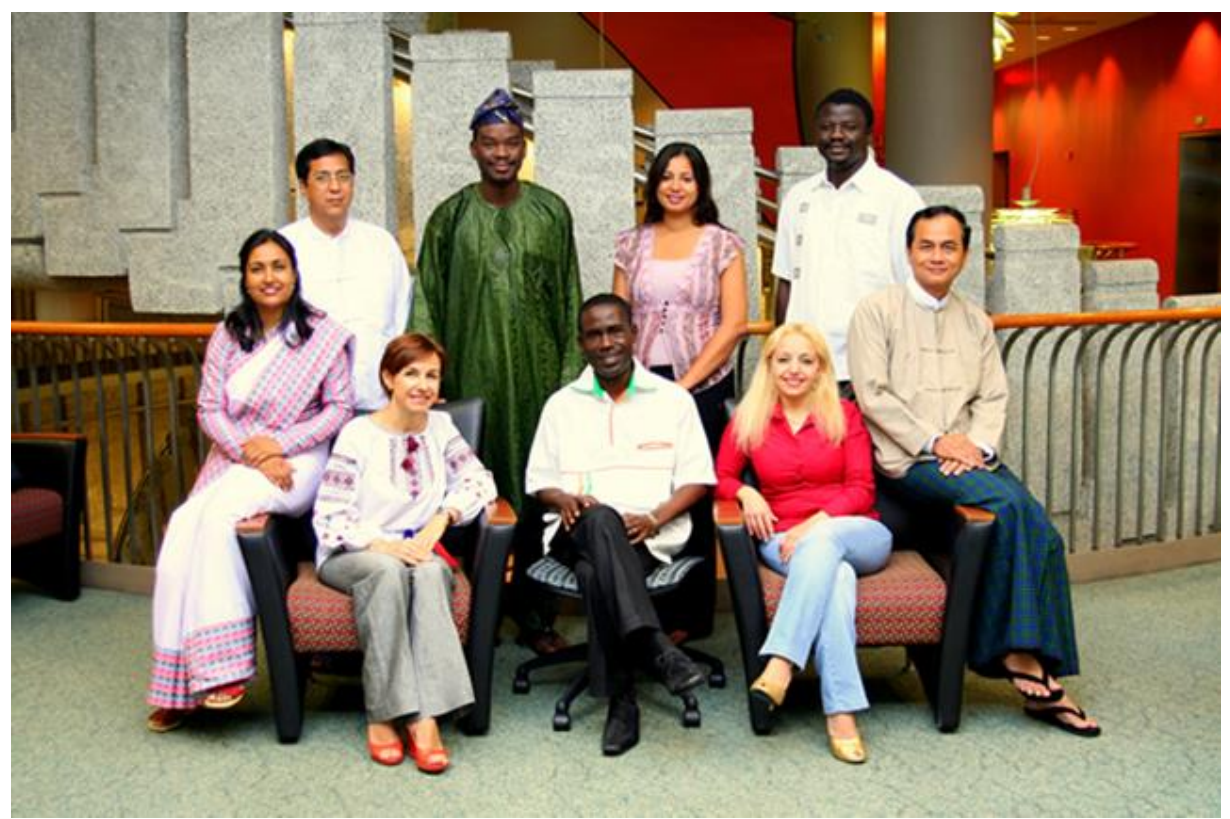

Dr. Komenan (front row, center) with his Hubert H. Humphrey fellowship alumni (Image credit: Emory University) 
Volunteerism and Leadership for Community Action) to help those in need," Dr. Komenan says.

On top of the US training program, Dr. Komenan also received a scholarship offer from Catholic University of Brussels, Belgium, where he obtained a diploma in Aesthetic and Plastic Surgery. Afterwards, he says, "I succeeded in the African Council of High Education's International Selection to be appointed a professor of Dermatology and Dermatology Surgery."

The dermatology expert is now also a proud member of Ivorian Society of Dermatology and Skin Surgery (SIDV), Francophone Dermatologist (ADF) and African Francophone Dermatology Society (SODAF). Via his years of experience in dermatology, Dr. Kassi has picked up different skills and knowledge along the way. His expertise ranges from general, autoimmune, tropical and infectious dermatology, as well as venereology and HIV/AIDS, wound care and cicatrization, dermatologic and oncology surgery, and also plastic, aesthetic and reconstructive surgery.

According to Dr. Komenan, key challenges faced by dermatologists are plenty, such as overcoming cancer. "What type of drugs can be used to destroy tumor cells? How to prevent skin cancers?" he asks rhetorically. In addition, he highlights other challenges: "What are the best products or methods for wound care? How to produce skin cells in vitro? How to set up a good preventive and treatment strategy for HIV infection in our setting?" he furthers.

"My personal goal is to develop dermatologic surgery in sub-Saharan Africa, and to develop multidisciplinary team on skin cancers both for treatment and research projects," Dr. Komenan shares. Moreover, he aims to use new academic tools to train students at the medical school in Abidjan and raise the awareness of skin cancer via his NGO in order to prevent skin cancers in Ivory Coast.

Understanding the importance of dermatologists in his country, Dr. Komenan also aims to improve his dermatology practice by getting new material such as laser, phototherapy, and others. Currently, he is working hard on various projects such as writing a thesis on psoriasis arthritis, and directing theses on multiple topics such as venous insufficiency, echo-Doppler, the knowledge and practical attitude of medical practitioner in Buruli ulcer, and also on the value of Dermatology Life Quality Index (DLQI) in keloid scar thesis.

When asked about current trends and future of dermatology research, he asserts, "In my opinion, I think skin cancers remain as a big concern in dermatology field to date." He adds, "It is the same for wound care, which still is one of the frequent risk factor of squamous cell carcinoma in sub-Saharan Africa. But the most current trends in dermatology research should be all subjects related to cosmetic or surgical dermatology such as rejuvenation products, techniques, laser, hyaluronic acid, and collagen. Research should focus on aesthetic without surgery."

At present, Dr. Kassi Komenan is a Professor of Dermatology-Venerology in Department of Dermatology and Infectiology, Université Félix Houphouët-Boigny, Abidjan, Ivory Coast. Dr. Komenan and his colleagues published their article entitled "Unusual presentation of a cutaneous leiomyoma of the neck simulating a goiter" in this issue of JSD (pages 14-16). 